\title{
Self-Disclosure as a Public Health Intervention
}

\author{
Matthew Carriero Johnson ${ }^{1}$
}

Received: 24 January 2021 / Accepted: 27 April 2021 / Published online: 10 May 2021

(C) Academic Psychiatry 2021

In a recent therapy session, my 79-year-old patient with a stable psychotic disorder informed me of her socially distanced holiday in her typical blunted affect. She then repeatedly inquired about mine. I felt my stomach turn, a common experience for me when faced with personal inquiry. Responses to self-disclosure in the voices of my attendings came to mind ranging from the imaginative, "what did you picture my holiday was like?" to an emphasis on the therapeutic relationship, "what makes you curious about my experience now?" I have yet to suppress the thought that I should respond as a person, metaphorically removing my psychiatrist hat, or perhaps putting it on backwards. Surely, some inquiry is a social grace that warrants an authentic response. I am not the cold blank slate upon which patients reflect their emotions. As a resident psychiatrist, a new father, partner, and caregiver, I am increasingly aware of the fluidity of my identity as opposed to one separated into discrete roles. The emerging psychiatrist within me cannot help but interpose-what am I missing (in me, in her, or between us), by avoiding self-disclosure? I felt lonely and wondered if this reflected concern for her well-being given her isolation. Facing personal inquiry is a fork in the road of therapeutic approach that reveals conflict in my identity as an emerging therapist and physician.

I responded to her inquiry with "it was good, thanks for asking" and attempted to explore her inquiry. I politely steered the conversation away landing upon coronavirus, which as a mutual experience felt surprisingly safe as a topic of personal discussion. The very intensity of the pandemic's effect on human functioning helps us relate to one another over this shared experience, one qualitatively similar though far from quantitatively equal. Well shielded by my medical knowledge, defense of intellectualization, and my scheduled vaccination, I inquired into mask use, social distancing, and vaccination. She admitted hesitancy to receive vaccination for

Matthew Carriero Johnson

mjohns22@bidmc.harvard.edu

Beth Israel Deaconess Medical Center, Boston, MA, USA concern of side effects. "What in the world are you waiting for?" was a thought I recall. In this session, I responded instead, "when we meet next, I will have received my vaccination. I am happy to share my experience and report any side effects if that would be helpful." My offer was reflexive and devoid of the anxiety I experienced with her initial inquiry into my holiday. Individually and in supervision, I sought to explore the discrepancies in my emotional experience, ease of response, and appropriateness of disclosure about vaccination.

Despite my initial comfort in the disclosure of my vaccination plans, on further reflection, I began to doubt the appropriateness of this disclosure as well. My purpose was to utilize my own experience to promote vaccination to a vulnerable individual; however, I worried that this intervention was paternalistic and lacking in evidence base. Feelings of imposterism, repressed from intern year, crept in; "surely I am overstepping. As a psychiatrist, this is not my identity, my role, or my place!" I felt guilt and uncertainty. Among patients seeking therapy, such a self-disclosure may introduce the clinician's personal experience into the therapeutic space. The cost is time and/or minimization of the patient's own experience and emotions. There is a risk of pulling into conscious awareness the inherent power dynamic between patient and clinician, inviting feelings of jealousy, anger, and devaluation. In regard to my patient, I wondered whether my disclosure was fueled by my own self-interest; first for vaccination, relief for the safety of me and my family, or excitement for the presumed end of a socially distanced lifestyle. Perhaps, I was swept up in the posting of deltoids and vaccine cards on social media in the name of advocacy. There was certainly guilt in my current access to vaccination as a young, healthy, White male with stable housing and health insurance. In response to my feelings of guilt, imposterism, and powerlessness, I felt a compelling need to offer something - a piece of myself to comfort or perhaps shield her from fear, worry, and medical vulnerability.

While different from the medical specialties facing coronavirus on the front lines, psychiatry as a field is also charting new waters. I experience this as a pull for change in the therapeutic relationship. There is risk in stepping outside our usual 
dynamic conflicting with my recognition of the humaneness within small self-disclosures [1]. Exploring the meaning of disclosure as an intervention in the therapeutic relationship is not a new phenomenon. Self-disclosure has the opportunity to strengthen the therapeutic relationship if navigated correctly [2]. The arguable appropriateness of my vaccination disclosure and discussion of my experience likely depends on the clinical scenario and the hat I am wearing [3]. I recognize my disclosure of vaccination not only as intimately human for the purpose of connection but also as an intervention. As a psychiatrist engaging in integrated treatment, there is an argument for the justification of vaccination disclosure. I share concern and responsibility for my patient's medical vulnerability and have a role in promoting healthy functioning. The pandemic has reminded me of the fluidity of identity and reemphasizes roles thought long forgotten. While my self-disclosure was a way of connecting to the patient through our shared experience of the pandemic, it also stands for an initially unconscious reminder of the roots of my medical training. Early work in community-integrated health clinics, volunteer work, and curricula in medical ethics and public health solidified the importance of public health advocacy. My self-disclosure was an enactment of my role in public health: providing education and vaccine promotion as an intervention.

The self-disclosure in this encounter served as a vehicle for self-reflection and exploration into my growth as a practitioner fostered by group and individual supervision. I hope my experience of self-disclosure regarding vaccination incites reflection and discussion among psychiatrists. In doing so, may it also serve as a call to arms for fellow mental health clinicians to join the fight in supporting our vulnerable patient population's access to vaccination.

Acknowledgements Dr. Pamela Peck and Dr. Adam Stern.

\section{Declarations}

Disclosures The author states that there is no conflict of interest.

\section{References}

1. Kahn MW. Pandemic and persona. N Engl J Med. 2020;383(1):1-2.

2. Renik O. Playing one's cards face up in analysis: an approach to the problem of self-disclosure. The Psychoanalytic Quarterly. 1999;68(4):521-39.

3. Henretty JR, Levitt HM. The role of the therapist self-disclosure in psychotherapy: a qualitative review. Clin Psychol Rev. 2010;30:6377.

Publisher's Note Springer Nature remains neutral with regard to jurisdictional claims in published maps and institutional affiliations. 